then the madness provides an excuse.

Ms Radden describes the case of a sniper who shot many people from the tower of the University of Texas before being kilied by the police. At autopsy he was found to have a brain tumour. Suppose that the tumour caused the sniper to hate people. Ms Radden believes that we would want to excuse the sniper on the grounds that although he may be able to give reasons for why he acted in that way (for example his hatred of people), he would be ignorant of his real reason for so acting (his tumour). On her view it is the ignorance of this real reason that is at the root of our excusing him.

But do any of us know the real reasons why we act as we do? Am I writing this because I like to think about philosophy, or to please the editor or because of a particular configuration of the chemicals and connections in my brain? Why does the brain tumour excuse, but my brain state does not? I suspect that we can only give an adequate answer in terms of an account of mental illness. The sniper is ill and I am not.

If this is true it undermines Ms Radden's position, because it would make her analysis of ignorance dependent on an analysis of illness. But her whole enterprise is to account for the excusing effect of madness without recourse to the concept of illness.

The same criticism can be made for the other pillar of her edifice: compulsion. If we are to say that one act is compelled by a person's mental state, but that another is not, we need to give an account of human action which can locate the essential difference. It is difficult to see how this could be done without involving the concept of illness.

My own belief, which I have come to only by reading this book, is that we must account for why madness may excuse wrongdoing through an analysis of madness as illness. This is the position which Ms Radden is out to attack. As in most good books on philosophy I found the examples more powerful than the arguments.

R A HOPE

Editorial Associate, Fournal of Medical Ethics, Wellcome Training Fellow in Psychiatry.
Which Babies Shall Live? Humanistic Dimensions of the Care of Imperilled Newborns

Editors, Thomas H Murray, Arthur L Caplan, 240 pages, Clifton, New Jersey, \$US34.50, Humana Press, 1985.

Making a decision about whether a neonate will live or die is both topical and emotive. How to determine criteria to establish exactly what decision should be made has much concerned practising doctors and ethicists, particularly in the past few decades. Which Babies Shall Live? makes no attempt to answer the question it sets, nor to resolve the dilemmas it poses. It is the result of a day-long seminar, organised by the Hastings Center, the Montefiore Hospital and Medical Center, and the New York Council for the Humanities, (no date supplied) concerned with 'taking a vacation ... from pretending to know the answers'. The organisers therefore turned to the humanities which, the editors tell us, have 'the deepest insights into the underground river of our ethos . . . I I am not sure they were right.

The contributors come from philosophy, bioethics, history, moral theology and literature (with one medical doctor thrown in to bring us up to date on neonatology). Some of the papers are slight, some out of touch with reality. Anyone who can talk about our judgements being 'temperated' as Margaret O'Brien Steinfels does, does not deserve to be read; and Leslie A Fiedler says of himself that he is 'more at home in the world of words and metaphor than fact, which is to say, an expert, if at all, in reality once removed'. His paper justifies this. Nevertheless, the editors see fit to have Ruth Macklin write a commentary on it. There are a number of commentaries but all on the less controversial or substantial issues. For example, there is no commentary on John D Arras's 'Toward an Ethic of Ambiguity', a paper which addresses itself to the extraordinary complexity of the whole issue of decision-making in the case of handicapped neonates; nor on Thomas H Murray's excellent discussion of suffering and neonatal intensive care.

Arras shows how difficult it is to establish 'the best interests of the child' and argues cogently that it is often not possible to judge whether life-saving procedures would be 'in the best interests of the child'. He considers that a better criterion is 'whether the child's impoverished level of existence is worth sustaining'. He shows that the 'issue is ... shot through with ethical ambiguity. Most anomalous children should be treated, some should be allowed to die. Substantive principles are available, but their application is fraught with difficulty and danger'. It seems to me that this book should have taken 'ethical ambiguity' as its title because in many cases that is what the contributors discuss.

Much of the volume is about the Baby Doe regulations of the US Department of Health and Human Services. These were formulated after a disputed decision not to treat a Down's syndrome neonate with a tracheo-oesophageal fistula and a possible heart anomaly. There is agreement in the book that a way to ensure treatment for Down's syndrome babies is necessary but it was felt that regulation was not the answer, and that, at any rate, the Baby Doe regulations were too narrow to be used for all possible neonatal handicaps.

Nancy Dubler discusses the right to privacy of patients about whom these decisions are being made. The problem, one which most of the authors tackle, is the right of an adult to make a decision about a neonate. She shows that the right of privacy has been 'bent and battered into supporting the concept that incompetent people must be protected from the rigid and mechancial imposition of medical care'. She provides no answers as to who should make these decisions although she makes clear who should not.

David H Smith seems to me to sum up the attitudes of many in this volume. 'We owe [a defective baby] respect and hope, care and comfort for his body, fair play and due process'. The trouble is we never find out what is fair play or due process.

The final section is somewhat more empirical as it is a report of a survey among health professionals about the treatment of the 'castastrophically ill newborns'. It deals with attitudes towards the US Department of Health and Social Security regulations about Baby Doe, and even though the final regulations came out after the survey was completed, the survey still makes interesting reading.

Caplan, in his conclusion, says that 'those who have carefully read through each of these papers may come away with an overinflated view of what the humanities can or ought be expected to 
do'. I did not.

DR VIVIANNE DE VAHL DAVIS

Lecturer in Medical Ethics, New South Wales Institute of Technology, PO Box 123, NSW 2007, Australia.

\section{Medical Ethics in Antiquity - Philosophical Perspectives on Abortion and Euthanasia}

Paul Carrick, 242 pages, Dordrecht, Holland, £27.95, Reidel Publishing Company, 1985.

Why bother to explore the origins of Western medical ethics? With the pressing and complex problems of bioethics today "who can afford the luxury of mounting the carousel of history for yet another ride full circle from past to present'? Having moved addictively through Carrick's study, I appreciate the vigour of his response: 'Who can afford not to?' Carrick writes his philosophical history with a style that engages the reader in a dialogue with Pythagoras, Plato, Aristotle, Galen and Seneca. More provocative is the search for the real Hippocrates whose identity is not yet established by historical evidence.

The social and scientific setting of Greek medicine is explored with two central questions asked: what scientific, socio-economic, religious and moral constraints did the average fifth or fourth century BC Greek physician experience in his daily practice of medicine and how did these factors shape his attitudes and conduct towards his patients and towards his community? Carrick does not just trip lightly over a plethora of mute historical facts; rather he unravels with rigour the presuppositions for ancient Greek and Roman beliefs about euthanasia, abortion and infanticide. The challenge to the reader is temporarily to adopt 'a fresh conceptual orientation to fully penetrate the logic of the pagan mind' on these issues. In recognising the multiple social, cultural, and religious factors forming the beliefs of the ancients, the contemporary reader can begin more assiduously to appreciate the complexity in the formation of moral beliefs in medicine.

Carrick is intent on dispelling some prevalent myths about the ancients particularly the myths of moral uniformity among ancient physicians, the myth of dedication to the imperatives of the Hippocratic Oath and the myth that physicians constituted an elite professional group looked on with admiration by Greek and Roman lay persons. The reader is confronted with a picture of philosophical pluralism in ancient Greece and Rome. The positions of Pythagoreans are starkly contrasted with those of Plato, Aristotle and Seneca on issues of abortion and euthanasia. Ancient texts are shown to provide a diverse range of publicly admitted reasons for the justification of either infanticide or abortion which make contemporary debates about conditions for abortion seem timid by comparison! The average Greek physician probably did not swear to uphold the famous Oath of Hippocrates. 'He may never have even heard of it!' For those sceptical of such debunking, Carrick is skilled and sensitive at showing how the process of unmasking illusions about the past is a necessary step to intellectual liberation. In the domain of medical ethics today it becomes a form of evasion to continue believing that a long revered Hippocratic tradition of medicine and ethics has been supplanted by a slipshod pluralism of the late 20th century. Misleading arguments by authorities based on alleged ancient medical tradition need exposing. A sense of confidence emerges in contemporary efforts more honestly to appraise our ethical ancestry. Carrick's final message may well be that there is wisdom to be found in the ancients and applied to the present but it is not the comfortable wisdom that for too long we have been taught.

DOLORES DOOLEY

College Lecturer in Philosophy and Medicine, University College, Cork, Ireland.

\section{Why Won't They Talk to me?}

Linward Productions Limited, PO Box 63, Shepperton Studio Centre, Studios Rd, Shepperton, Middlesex TW17 0QD.

$£ 295$ + VAT per set of five videos each lasting about 25 minutes.

This set of five video programmes sets out to improve communications between those who are seriously ill and dying and their carers, particularly doctors, medical students, nurses and social workers. The series demonstrates good and bad ways of talking with patients, using the skills of a group of $\mathscr{\mathscr { C }}$ actors who have been specially trained to recreate the emotions and reactions of patients facing serious illness. The presenters are Dr Rob Buckman, a consultant medical oncologist and also well known as a television wit, and $\mathrm{Dr}$ Peter Maguire, a consultant psychiatrist, whose special interest is communication skills in patient care.

On the basis of the compilation tape sent for review the series is clearly $\vec{\omega}$ beneficial as a teaching aid, demonstrating in a vivid and dramatic way both crass and incompetent, and $\overparen{D}$ friendly and effective ways of talking $\vec{N}$ about these painful issues. Again, $\omega$ judging on the basis of the compilation $\vec{G}$ tape there is not much discussion or $\infty$ analysis of the ethical issues raised, so 음 readers of this journal would be likely to want to supplement the content of the $c s$ tapes if they used them for teaching $\frac{\mathbb{D}}{O}$ purposes. On the other hand as a $\mathbb{D}$ starting point for teaching concerning the doctor/patient relationship, truthtelling, dealing with conflict, and associated issues in medical ethics, the tapes can be heartily recommended ase sympathetic, practical and clinically based introduction. However, althougt they are apparently subsidised, they are rather expensive - perhaps their expense would be justifiable within the context of libraries and teaching centres.

RAANAN GILLON

Editor, Journal of Medical Ethics and Director, Imperial College Health Centre, London SW7 INA.

\section{Abortion: Medical Progress and Social Implications}

Ciba Foundation Symposium 115, 285 工 pages, Avon, The Pitman Publishing 을. Co Ltd, 1985.

'The need to check the unlimited growth of the world's population has been accepted by most responsible $\omega$ authorities . . . ' So states David Baird in his introduction to the papers whicheo form the basis of the Ciba symposium $\bar{\Phi}$ on abortion. If one accepts his first? statement without enquiring as to what $\square$ constitutes a responsible authority or $\overline{0}$ whether there is any evidence that $\overrightarrow{\mathbb{Q}}$ unlimited growth of the world's $\frac{?}{\mathbb{D}}$ population is indeed the actuale consequence if birth control methods 